\title{
Predictors of adolescent weight status and central obesity in rural South Africa
}

\author{
Elizabeth W Kimani-Murage ${ }^{1,2, *}$, Kathleen Kahn ${ }^{1,3,4}$, John M Pettifor ${ }^{5}$, \\ Stephen M Tollman ${ }^{1,3,4}$, Kerstin Klipstein-Grobusch ${ }^{6}$ and Shane A Norris ${ }^{5}$ \\ ${ }^{1}$ MRC/Wits Rural Public Health and Health Transitions Research Unit (Agincourt), School of Public Health, \\ Faculty of Health Sciences, University of the Witwatersrand, Johannesburg, South Africa: ${ }^{2}$ African Population \\ and Health Research Centre (APHRC), PO Box 10787, 00100 Nairobi, Kenya: ${ }^{3}$ Umeå Centre for Global \\ Health Research, Department of Public Health and Clinical Medicine, Umeå University, Sweden: ${ }^{4}$ INDEPTH \\ Network, Accra, Ghana: ${ }^{5}$ MRC Mineral Metabolism Research Unit, Department of Paediatrics, Faculty of Health \\ Sciences, University of the Witwatersrand, Johannesburg, South Africa: ${ }^{6}$ School of Public Health, Faculty of \\ Health Sciences, University of the Witwatersrand, Johannesburg, South Africa
}

Submitted 31 May 2010: Accepted 4 January 2011: First published online 28 February 2011

\begin{abstract}
Objective: To investigate predictors of adolescent obesity in rural South Africa. Design: Cross-sectional study. Height, weight and waist circumference were measured using standard procedures. Overweight and obesity in adolescents aged 10-17 years were assessed using the International Obesity Taskforce cut-offs, while the WHO adult cut-offs were used for participants aged 18-20 years. Waistto-height ratio of $>0.5$ defined central obesity in those at Tanner stages 3-5. Linear and logistic regression analysis was used to evaluate risk factors.

Setting: Agincourt sub-district, rural South Africa.

Subjects: Participants ( $n$ 1848) were aged 10-20 years.

Results: Combined overweight and obesity was higher in girls (15\%) than boys (4\%), as was central obesity ( $15 \%$ and $2 \%$, respectively). With regard to overweight/ obesity, fourfold higher odds were observed for girls and twofold higher odds were observed for participants from households with the highest socio-economic status (SES). The odds for overweight/obesity were $40 \%$ lower if the household head had not completed secondary level education. For central obesity, the odds increased $10 \%$ for each unit increase in age; girls had sevenfold higher odds $v$. boys; postpubertal participants had threefold higher odds $v$. pubertal participants; those with older mothers aged $50+$ years had twofold higher odds $v$. those whose mothers were aged 35-49 years; those in highest SES households had twofold higher odds $v$. those in lowest SES households.

Conclusions: In rural South Africa, adolescent females are most at risk of obesity which increases with age and appears to be associated with higher SES. To intervene effectively, it is essential to understand how household factors influence food choice, diet and exercise.
\end{abstract}

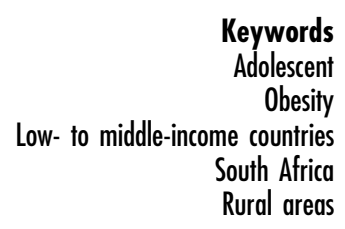

Obesity is increasingly a public health concern in both high-income and low- to middle-income countries (LMIC), but the prevalence is expected to increase more rapidly in LMIC $^{(1,2)}$. Obesity in these countries is associated with a rise in chronic diseases such as hypertension, CHD, type 2 diabetes and certain types of cancer, which contribute substantially to the burden of disease ${ }^{(2)}$. Childhood and adolescent obesity is of particular concern, as obese children and adolescents are more likely to become obese adults and hence are at a higher risk of metabolic diseases $^{(3,4)}$. In South Africa, high levels of overweight/ obesity have been documented among adults ${ }^{(5)}$. There is also some evidence of high levels of overweight/obesity among children and adolescents ${ }^{(6,7)}$. In a recent study in Agincourt, rural South Africa, we described patterns of overweight/obesity and central obesity among children and adolescents aged 1-20 years. The prevalence of combined overweight and obesity was high in adolescent girls, reaching a peak of $25 \%$ at age 18 years, while central obesity was also high in adolescent girls, increasing with pubertal development and reaching a peak of $35 \%$ in girls at Tanner stage $5^{(8)}$.

Predictors of child and adolescent obesity have been described in various studies ${ }^{(9,10)}$ and seem to involve a complex array of influential domains: community, family/ household, individual and genetic. In a literature review 
conducted in 2001, Davison and Birch ${ }^{(10)}$ described an ecological model of predictors of child weight status. In this model, child characteristics interact with familial/ household and societal/community factors to influence weight status in a child. The child's behavioural patterns including dietary intake, sedentary behaviours and physical activity predict his/her weight status. Furthermore, child characteristics including sex, age and genetic susceptibility to gaining weight moderate the impact of child behavioural patterns on the development of obesity. Family/household factors such as socio-economic factors, parenting styles, parental dietary patterns and sibling interactions influence a child's weight status through shaping the development of child behavioural patterns $^{(9,10)}$. Community and wider societal and environmental factors influence the weight of the child through influencing the child's behavioural patterns and family factors $^{(10)}$

There are limited studies describing the predictors of child and adolescent obesity in rural South Africa ${ }^{(11)}$. The present study aimed to assess associations between child-, maternal-, household- and community-level factors and weight status and central obesity among adolescents aged 10-20 years, randomly selected from a rural South African setting.

\section{Study setting and population}

The study was conducted in the Agincourt sub-district of Mpumalanga Province in rural north-east South Africa, close to the country's border with Mozambique. It was nested within the Agincourt health and sociodemographic surveillance system (HDSS). The Agincourt HDSS is a multi-round prospective community study established in 1992, covering the entire Agincourt sub-district. Until 2007 when the site was extended, the HDSS followed some 70000 people living in 11500 households in twenty-one villages, about $30 \%$ of whom were of Mozambican origin. The Mozambicans entered South Africa mainly as refugees in the early to mid-1980s following the civil war in Mozambique. Despite voluntary repatriation programmes, most elected to remain as so-called self-settled former refugees. They are also Tsonga-speaking, have much in common culturally and have integrated to large extent with the host South African population. Despite this, the Mozambicans remain a vulnerable subgroup within the broader community ${ }^{(12,13)}$.

While there have been government development initiatives, infrastructure remains limited in Agincourt. The area is dry with household plots too small to support subsistence farming. The poverty level is high ${ }^{(14)}$ and labour migration is widespread, involving up to $60 \%$ of working age men and increasing numbers of women ${ }^{(15,16)}$. The Agincourt HDSS and study area have been described in detail previously ${ }^{(8,17)}$.

\section{Data and methods}

We conducted a growth survey between April and July 2007. The survey targeted 4000 children and adolescents aged 1-20 years -100 males and 100 females for each year of age - comprising about $12 \%$ of the total Agincourt HDSS population within this age spectrum. Participants had lived in the study area at least $80 \%$ of the time since birth, or since 1992 when enrolment in the Agincourt HDSS began. A total of 3511 children and adolescents (close to $80 \%$ of the sample) participated in the study ${ }^{(8)}$. All survey participants aged 10-20 years ( $n$ 1848) were included in the present analysis.

\section{Measurements}

Anthropometric measurements were carried out on all participants while pubertal assessment was obtained from those aged 9-20 years. Height was measured using a stadiometer (Holtain, Crymych, UK) calibrated in millimetres. Weight in kilograms (to one decimal point) was determined using a mechanical bathroom scale (Hanson; Bathroom Trends Limited, Epsom, UK), and waist circumference was measured in millimetres using an inelastic tape measure. All measurements were taken according to standard procedures $^{(8,18)}$. Adolescents self-rated their pubertal stage using the Tanner 5-point pubertal self-rating scale that reflects physical development based on external primary and secondary sex characteristics ${ }^{(19)}$. This self-rating scale has been validated for black South Africans ${ }^{(20)}$. Genital development in boys and breast development in girls were used to define the stages in the present study. Data collection procedures are detailed in a previous publication ${ }^{(8)}$.

\section{Explanatory variables}

Explanatory variables used in the study were obtained from the Agincourt HDSS. This involves systematic annual recording of all births, deaths and migration events occurring in the Agincourt sub-district since 1992. Additional data are collected as special census modules nested within the annual update rounds. These include education, child social grant uptake, union status and food security. An asset survey conducted in each household every two years provides a relative measure of household socio-economic status (SES) ${ }^{(17)}$.

Child-level factors included age, sex and pubertal development stage; maternal-level factors included mother's age, nationality, highest education level, marital/union status and co-residence with the child; household-level factors included age, sex and highest education level of the household head and his/her relationship to the child, household food security and household SES; area of residence (predominantly South African or Mozambican) was used as a proxy for community-level characteristics.

Definitions of the explanatory variables are provided in Table 1. Pubertal stage was constructed with Tanner stage 1,2-4 and 5 defined as pre-pubertal, pubertal and 
post-pubertal, respectively. Food insecurity was defined as reporting not having enough food to eat in either the last month or the last year, whereas food-secure households were those households reporting sufficient to eat both in the last month and last year. Household wealth index was constructed from household assets ${ }^{(21)}$ including type and size of dwelling; water and sanitation facilities; electricity; modern assets such as a fridge and television; transport assets such as a car; communication assets such as a telephone; and livestock such as cattle. A composite score for the wealth indicator was constructed. Household wealth tertiles were generated from the composite SES score using STATA's xtile command and labelled as 'lowest' (lowest third), 'medium' and 'highest' (highest third).

\section{Outcome measures}

Outcome measures included BMI-for-age Z-score, waistto-height ratio $Z$-score, combined overweight and obesity, and central obesity. BMI-for-age $Z$-scores were generated using the WHO 2007 reference, using the WHO AnthroPlus software (WHO, Geneva, Switzerland) ${ }^{(22)}$. Age- and sexspecific waist-to-height ratio $Z$-scores were sample specific. Overweight and obesity in children aged 10-17 years were determined using the absolute age- and sex-specific cut-offs for BMI recommended by the International Obesity Taskforce ${ }^{(23)}$. These are defined to pass through BMI of 25 and $30 \mathrm{~kg} / \mathrm{m}^{2}$ at 18 years for overweight and obesity, respectively. For adolescents aged 18-20 years, adult cut-off points for BMI of $\geq 25$ and $\geq 30 \mathrm{~kg} / \mathrm{m}^{2}$ for overweight and obesity, respectively, were used. Overweight and obesity were combined in the analysis owing to the limited number of participants who were classified as obese. Waist-to-height ratio cut-off of $>0.5$ was used to determine the presence of central obesity in both boys and girls in Tanner stages $3-5^{(24)}$.

Underweight status was determined among the participants to assess its influence on the outcomes. This was defined by the 5 th percentile using the WHO 2007 reference for BMI-for-age $Z$-scores ${ }^{(22,25)}$. About $4 \%$ of the study participants were classified as underweight. However most of those underweight were in lower ages and were in pubertal stages 1 and 2, indicating that they were still growing. Exclusion of these children altered the results only marginally; thus they were retained in the final analysis.

\section{Etbical clearance}

For the growth study, signed informed consent was obtained from the parent/caregiver for children and adolescents aged less than 18 years and from the adolescents aged 18-20 years themselves, while assent was also obtained from adolescents aged less than 18 years. Verbal informed consent is routinely obtained from participants in the Agincourt HDSS. Ethical clearances for the growth survey (\# M070244) and the Agincourt HDSS (\# M960720) were granted separately by the University of the Witwatersrand Committee for Research on Human Subjects (Medical).

\section{Statistical analysis}

Data analysis was undertaken using the STATA statistical software package version 10.0 (StataCorp LP, College Station, TX, USA). Student's $t$ test was used to determine difference in means, while the $\chi^{2}$ test was used to determine difference in proportions. Univariate and multiple linear and logistic regression analyses were conducted with outcome variables (BMI-for-age $Z$-score, waist-to-height ratio $Z$-score, overweight/obesity, central obesity) and explanatory variables as described above, respectively. Missing values for each variable were allocated an independent category in the regression models to maintain all participants in the analysis. The variables affected included: mother's age (9\%), nationality (9\%) and education (21\%); household head's education (11\%) and relationship with the child $(<1 \%)$; food security ( $4 \%)$ and SES (2\%). Only explanatory variables significantly associated with the outcome variable at the $10 \%$ significance level in the univariate analysis were included in the multiple regression analysis. A two-sided $P$ value of $<0.05$ was considered statistically significant.

\section{Results}

The study sample comprised 903 (49.6\%) boys and 945 $(50 \cdot 5 \%)$ girls aged $10-20$ years; mean age was $14.6(95 \%$ CI $14 \cdot 43,14 \cdot 83)$ years. There was no significant difference in mean age by sex.

\section{Distribution of overweight/obesity and central obesity by explanatory variables}

The prevalence of combined overweight and obesity among participants aged 10-20 years was 10\%, while that of central obesity among participants in Tanner stages 3-5 was also $10 \%$. The following categories had significantly higher prevalence of either combined overweight and obesity or central obesity: 15 - to 20-year-olds $v$. 10- to 14-year-olds; girls $v$. boys; pubertal and post-pubertal $v$. pre-pubertal; those with older mothers; those with mothers of South African origin $v$, those with mothers of Mozambican origin or those who lived in villages inhabited predominantly by people of South African origin; those with the most educated household heads; and those from the highest SES households (all $P<0 \cdot 05$; Table 1 ).

\section{Multivariate analysis}

Predictors of BMI-for-age Z-scores, waist-for-height ratio $Z$-scores, overweight/obesity and central obesity are presented in Tables 2 and 3. Only variables that were significantly associated with the outcome measures at the $10 \%$ level of significance from univariate analysis are included in the tables. A test for collinearity among the variables included in the multivariate analysis was done; there was no 
Table 1 Distribution of combined overweight and obesity* for adolescents aged 10-20 years $(n$ 1848) and central obesityt for adolescents in Tanner stages 3-5 ( $n$ 1110) by various covariates, Agincourt sub-district, South Africa, 2007

\begin{tabular}{|c|c|c|c|c|c|c|}
\hline Variable & $n$ & $\%$ & $\begin{array}{l}\text { Combined overweight } \\
\text { and obese }(\%)\end{array}$ & $n$ & $\%$ & $\begin{array}{c}\text { Central } \\
\text { obesity (\%) }\end{array}$ \\
\hline \multicolumn{7}{|l|}{ CHILD CHARACTERISTICS } \\
\hline Age (years) & & & $P=0.003$ & & & $P=0.014$ \\
\hline $10-14$ & 944 & $51 \cdot 1$ & $7 \cdot 5$ & 285 & $25 \cdot 7$ & $6 \cdot 3$ \\
\hline $15-20$ & 904 & $48 \cdot 9$ & $11 \cdot 6$ & 825 & $74 \cdot 3$ & $11 \cdot 4$ \\
\hline Sex & & & $P<0.001$ & & & $P<0.001$ \\
\hline Boy & 903 & $49 \cdot 6$ & $3 \cdot 5$ & 425 & $38 \cdot 3$ & $2 \cdot 4$ \\
\hline Girl & 945 & $50 \cdot 5$ & $15 \cdot 2$ & 625 & $61 \cdot 7$ & $14 \cdot 9$ \\
\hline Pubertal status & & & $P<0.001$ & & & $P<0.001$ \\
\hline Pre-pubertal & 283 & $15 \cdot 4$ & $4 \cdot 2$ & - & & - \\
\hline Pubertal & 1374 & $74 \cdot 6$ & $8 \cdot 4$ & 926 & $83 \cdot 4$ & $7 \cdot 4$ \\
\hline Post-pubertal & 184 & $10 \cdot 0$ & $26 \cdot 6$ & 184 & $16 \cdot 6$ & $23 \cdot 9$ \\
\hline \multicolumn{7}{|l|}{ MATERNAL CHARACTERISTICS } \\
\hline Age, current (years) & & & $P=0.015$ & & & $P=0.011$ \\
\hline $15-34$ & 302 & $8 \cdot 0$ & $8 \cdot 3$ & 614 & $61 \cdot 7$ & $8 \cdot 2$ \\
\hline $35-49$ & 1001 & $59 \cdot 7$ & $8 \cdot 2$ & 103 & $10 \cdot 3$ & $10 \cdot 7$ \\
\hline $50+$ & 373 & $22 \cdot 3$ & $13 \cdot 1$ & 279 & $28 \cdot 0$ & $14 \cdot 7$ \\
\hline Nationality & & & $P=0.023$ & & & $P=0.087$ \\
\hline South African & 1131 & $67 \cdot 5$ & $10 \cdot 4$ & 709 & $71 \cdot 2$ & $11 \cdot 3$ \\
\hline Mozambican & 544 & $32 \cdot 5$ & $7 \cdot 0$ & 287 & $28 \cdot 8$ & $7 \cdot 7$ \\
\hline Education & & & $P=0.949$ & & & $P=0.568$ \\
\hline No formal education & 547 & $37 \cdot 4$ & $9 \cdot 0$ & 340 & $38 \cdot 9$ & $8 \cdot 8$ \\
\hline Some education below secondary certificate & 659 & $45 \cdot 1$ & $8 \cdot 5$ & 393 & $44 \cdot 9$ & $9 \cdot 7$ \\
\hline Secondary and higher & 255 & $17 \cdot 5$ & $9 \cdot 0$ & 142 & $16 \cdot 2$ & $12 \cdot 0$ \\
\hline Marital/union status & & & $P=0.862$ & & & $P=0.655$ \\
\hline Currently in union & 944 & $51 \cdot 1$ & $9 \cdot 6$ & 562 & $50 \cdot 6$ & $10 \cdot 5$ \\
\hline Not in union & 904 & 48.9 & $9 \cdot 4$ & 548 & $49 \cdot 4$ & $9 \cdot 7$ \\
\hline Co-residence with child & & & $P=0.875$ & & & $P=0.547$ \\
\hline Alive, co-residing & 1536 & $83 \cdot 1$ & $9 \cdot 5$ & 921 & $83 \cdot 0$ & 10.5 \\
\hline Alive, not co-residing & 163 & $8 \cdot 8$ & $10 \cdot 7$ & 96 & $8 \cdot 7$ & $8 \cdot 3$ \\
\hline Dead & 149 & $8 \cdot 1$ & $8 \cdot 7$ & 93 & $8 \cdot 4$ & $7 \cdot 5$ \\
\hline \multicolumn{7}{|l|}{ HOUSEHOLD CHARACTERISTICS } \\
\hline Age of $\mathrm{HHH}$ (years) & & & $P=0.296$ & & & $P=0.435$ \\
\hline $15-49$ & 739 & $40 \cdot 0$ & $8 \cdot 7$ & 414 & $37 \cdot 4$ & $9 \cdot 2$ \\
\hline $50+$ & 1107 & $60 \cdot 0$ & $10 \cdot 1$ & 694 & $62 \cdot 6$ & $10 \cdot 7$ \\
\hline Sex of $\mathrm{HHH}$ & & & $P=0.131$ & & & $P=0.343$ \\
\hline Male & 1207 & $65 \cdot 4$ & $8 \cdot 8$ & 717 & $64 \cdot 7$ & $9 \cdot 5$ \\
\hline Female & 639 & $34 \cdot 6$ & $11 \cdot 0$ & 391 & $35 \cdot 3$ & $11 \cdot 3$ \\
\hline Education of $\mathrm{HHH}$ & & & $P=0.022$ & & & $P=0.318$ \\
\hline No formal education & 806 & $49 \cdot 1$ & $10 \cdot 3$ & 496 & $50 \cdot 5$ & $10 \cdot 3$ \\
\hline Some primary, completed primary, some secondary & 692 & $42 \cdot 2$ & $7 \cdot 4$ & 402 & $40 \cdot 9$ & $8 \cdot 2$ \\
\hline Secondary and higher & 143 & $8 \cdot 7$ & $14 \cdot 0$ & 84 & $8 \cdot 55$ & $13 \cdot 1$ \\
\hline HHH's relationship to child & & & $P=0.132$ & & & $P=0.660$ \\
\hline Parent & 1272 & $68 \cdot 8$ & $8 \cdot 8$ & 1272 & $69 \cdot 1$ & $10 \cdot 6$ \\
\hline Grandparent & 430 & $23 \cdot 3$ & $12 \cdot 9$ & 430 & $23 \cdot 3$ & $8 \cdot 9$ \\
\hline Other relative & 140 & $7 \cdot 6$ & $10 \cdot 0$ & 140 & $7 \cdot 6$ & $8 \cdot 3$ \\
\hline Enough food (last month/year) & & & $P=0.073$ & & & $P=0.051$ \\
\hline Yes & 1443 & $81 \cdot 2$ & $10 \cdot 4$ & 872 & $81 \cdot 5$ & $11 \cdot 3$ \\
\hline No & 335 & $18 \cdot 8$ & $7 \cdot 2$ & 198 & $18 \cdot 5$ & $6 \cdot 6$ \\
\hline SES (wealth index tertile) & & & $P=0.002$ & & & $P=0.074$ \\
\hline Lowest & 605 & $33 \cdot 4$ & $6 \cdot 8$ & 345 & $31 \cdot 7$ & $7 \cdot 9$ \\
\hline Medium & 603 & $33 \cdot 3$ & $9 \cdot 6$ & 364 & 33.5 & $9 \cdot 9$ \\
\hline Highest & 603 & $33 \cdot 3$ & $12 \cdot 8$ & 378 & $34 \cdot 8$ & $13 \cdot 0$ \\
\hline \multicolumn{7}{|l|}{ COMMUNITY FACTORS } \\
\hline Area of residence & & & $P=0.047$ & & & $P=0.712$ \\
\hline Predominantly South African & 1746 & 94.5 & $9 \cdot 9$ & 1063 & $95 \cdot 8$ & $10 \cdot 2$ \\
\hline Predominantly Mozambican & 102 & $5 \cdot 5$ & $3 \cdot 9$ & 47 & $4 \cdot 2$ & $8 \cdot \overline{5}$ \\
\hline
\end{tabular}

$\mathrm{HHH}$, household head.

*International Obesity Taskforce criteria $^{(23)}$ for those $<18$ years and $\mathrm{BMI} \geq 25 \mathrm{~kg} / \mathrm{m}^{2}$ for those $\geq 18$ years.

tWaist-to-height ratio of $>0 \cdot 5^{(24)}$.

significant collinearity. Additionally, interaction was tested between various variables significant at the univariate level; no significant interactions were found. Significant predictors of adolescent weight status and central obesity at the multivariate level were at child, maternal and household levels.

\section{Child factors}

All of the child-level factors examined (age, sex and pubertal development status) emerged as significant predictors of adolescent weight status and central obesity. After controlling for other covariates, for every increase in year of age, the 
Table 2 Determinants of BMI-for-age Z-score and combined overweight and obesity ${ }^{\star}$ in adolescents aged 10-20 years ( $n$ 1848), Agincourt sub-district, rural South Africa, 2007

\begin{tabular}{|c|c|c|c|c|c|c|}
\hline & \multicolumn{3}{|c|}{ BMI-for-age Z-scoret } & \multicolumn{3}{|c|}{ Overweight and obesity } \\
\hline & Coefficient & $95 \% \mathrm{Cl}$ & $P$ & OR & $95 \% \mathrm{Cl}$ & $P$ \\
\hline \multicolumn{7}{|l|}{ CHILD CHARACTERISTICS } \\
\hline Age & -0.00 & $-0.03,0.02$ & 0.790 & $1 \cdot 01$ & $0.94,1.07$ & 0.822 \\
\hline \multicolumn{7}{|l|}{ Sex } \\
\hline Boy (ref.) & 0 & & & $1 \cdot 00$ & - & \\
\hline Girls & 0.58 & $0.46,0.69$ & $<0.001$ & $4 \cdot 24$ & $2 \cdot 82,6 \cdot 38$ & $<0.001$ \\
\hline \multicolumn{7}{|l|}{ Pubertal status } \\
\hline Pre-pubertal (ref.) & 0 & & & $1 \cdot 00$ & - & \\
\hline Pubertal & $0 \cdot 31$ & $0 \cdot 14,0.48$ & $<0.001$ & $1 \cdot 40$ & $0 \cdot 71,2 \cdot 75$ & 0.331 \\
\hline Post-pubertal & $1 \cdot 07$ & $0 \cdot 77,1 \cdot 36$ & $<0.001$ & $4 \cdot 41$ & $1 \cdot 93,10 \cdot 10$ & $<0.001$ \\
\hline \multirow{2}{*}{\multicolumn{7}{|c|}{$\begin{array}{l}\text { MATERNAL CHARACTERISTICS } \\
\text { Age (vears) }\end{array}$}} \\
\hline & & & & & & \\
\hline \multicolumn{7}{|l|}{$\begin{array}{l}\text { Age (years) } \\
35-49 \text { (ref) }\end{array}$} \\
\hline $15-34$ & & & & $1 \cdot 39$ & $0 \cdot 83,2 \cdot 32$ & $0 \cdot 211$ \\
\hline $50+$ & & & & $1 \cdot 45$ & $0.96,2 \cdot 20$ & 0.075 \\
\hline \multicolumn{7}{|l|}{ Nationality } \\
\hline South African (ref.) & 0 & & & $1 \cdot 00$ & - & \\
\hline Mozambican & $-0 \cdot 10$ & $-0.25,0.05$ & $0 \cdot 176$ & 0.85 & $0.55,1 \cdot 31$ & 0.459 \\
\hline \multicolumn{7}{|l|}{ Education } \\
\hline No education (ref.) & 0 & & & & & \\
\hline Some education below secondary level & 0.05 & $-0 \cdot 11,0 \cdot 12$ & 0.517 & & & \\
\hline Completed secondary/tertiary & $0 \cdot 04$ & $-0 \cdot 18,0 \cdot 26$ & $0 \cdot 702$ & & & \\
\hline \multirow{2}{*}{\multicolumn{7}{|c|}{$\begin{array}{l}\text { HOUSEHOLD CHARACTERISTICS } \\
\text { Sex of HHH }\end{array}$}} \\
\hline & & & & & & \\
\hline \multicolumn{7}{|l|}{ Male (ref.) } \\
\hline \multicolumn{7}{|l|}{ Female } \\
\hline \multicolumn{7}{|l|}{ Education of $\mathrm{HHH}$} \\
\hline No education (ref.) & 0 & & & $1 \cdot 00$ & - & \\
\hline Some education below secondary level & $-0 \cdot 14$ & $-0.28,-0.00$ & 0.046 & $0 \cdot 60$ & $0.40,0.89$ & 0.012 \\
\hline Completed secondary/tertiary & $0 \cdot 14$ & $-0 \cdot 10,0 \cdot 38$ & 0.243 & $1 \cdot 11$ & $0 \cdot 61,2 \cdot 02$ & 0.737 \\
\hline \multicolumn{7}{|l|}{ Food security } \\
\hline Yes (ref.) & 0 & & & $1 \cdot 00$ & - & \\
\hline No & $0 \cdot 15$ & $-0.00,0.29$ & 0.052 & $1 \cdot 35$ & $0 \cdot 84,2 \cdot 16$ & $0 \cdot 216$ \\
\hline \multicolumn{7}{|l|}{ SES (wealth index tertile) } \\
\hline Lowest (ref.) & 0 & & & $1 \cdot 00$ & - & \\
\hline Medium & $0 \cdot 25$ & $0.11,0.39$ & 0.001 & $1 \cdot 40$ & $0 \cdot 90,2 \cdot 19$ & $0 \cdot 134$ \\
\hline Highest & $0 \cdot 28$ & $0 \cdot 14,0 \cdot 43$ & $<0.001$ & $1 \cdot 99$ & $1 \cdot 28,3.09$ & 0.002 \\
\hline \multirow{2}{*}{\multicolumn{7}{|c|}{$\begin{array}{l}\text { COMMUNITY FACTORS } \\
\text { Area of residence }\end{array}$}} \\
\hline & & & & & & \\
\hline Predominantly South African (ref.) & 0 & & & $1 \cdot 00$ & - & \\
\hline Predominantly Mozambican & -0.08 & $-0.34,0.17$ & 0.528 & 0.51 & $0 \cdot 17,1.51$ & $0 \cdot 227$ \\
\hline
\end{tabular}

$\mathrm{HHH}$, household head; ref., reference category.

*International Obesity Taskforce criteria ${ }^{(23)}$ for those $<18$ years and $\mathrm{BMI} \geq 25 \mathrm{~kg} / \mathrm{m}^{2}$ for those $\geq 18$ years.

tLinear regression.

fLogistic regression.

odds of central obesity increased by $10 \%(P=0 \cdot 041)$. Compared with boys, girls had higher BMI-for-age and waist-to-height ratio Z-scores, had fourfold higher odds of being overweight or obese, and sevenfold higher odds of having central obesity (all $P<0 \cdot 001$ ). Compared with pre-pubertal adolescents, pubertal and post-pubertal adolescents had higher BMI-for-age $Z$-scores and post-pubertal adolescents had higher waist-to-height ratio $Z$-scores; while post-pubertal adolescents had fourfold higher odds of overweight/obesity compared with pre-pubertal adolescents and threefold higher odds of having central obesity compared with pubertal adolescents (all $P<0 \cdot 001$; Tables 2 and 3).

\section{Maternal factors}

Among maternal factors included, only the mother's age was a significant determinant. Adolescents of older mothers aged $50+$ years had close to twofold higher odds of central obesity compared with adolescents whose mothers were aged 35-49 years $(P=0 \cdot 020$; Table 3$)$.

\section{Household factors}

After controlling for other covariates, significant householdlevel predictors included household head's highest education level, food security and SES. Compared with adolescents in households headed by someone with no formal education, adolescents in households where the household head had education below secondary level certificate had lower BMI-for-age $Z$-scores and had $40 \%$ lower odds of being overweight/obese (all $P<0 \cdot 05$ ). Adolescents in food-secure households had higher waistto-height ratio $Z$-scores $(P=0 \cdot 046)$. Compared with adolescents in the lowest SES households, those in the 
Table 3 Determinants of waist-for-height ratio Z-score for adolescents aged 10-20 years $\left(n\right.$ 1848) and central obesity ${ }^{\star}$ for adolescents in Tanner stages 3-5 ( $n$ 1110), Agincourt sub-district, rural South Africa, 2007

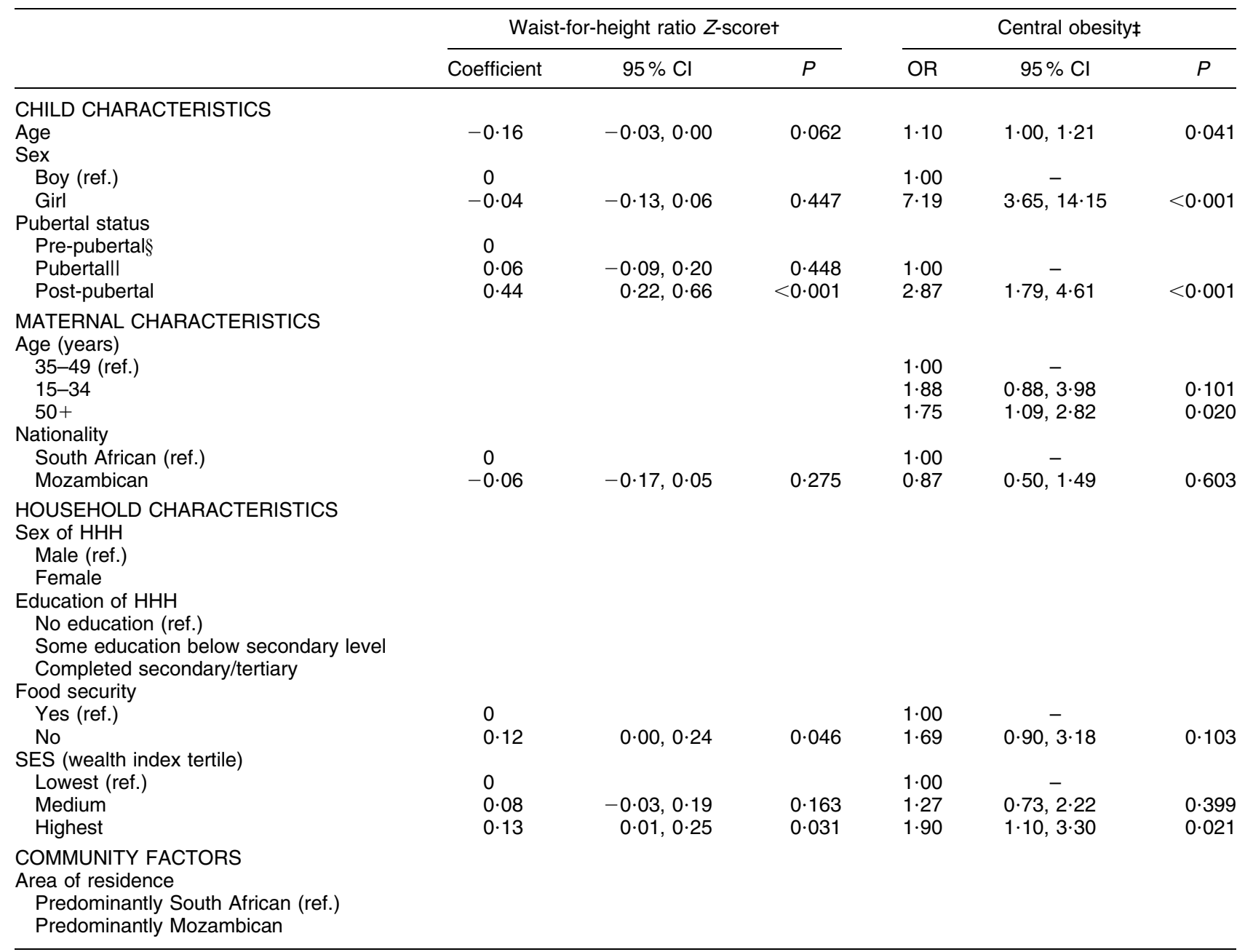

$\mathrm{HHH}$, household head; ref., reference category.

${ }^{*}$ Waist-to-height ratio of $>0 \cdot 5^{(24)}$.

tLinear regression.

‡Logistic regression.

§Pre-pubertal used as reference in the model for central obesity and waist-for-height Z-score for adolescents aged 10-20 years.

IIPubertal used as reference in the model for central obesity for adolescents in Tanner stages 3-5.

medium and the highest SES households had higher BMIfor-age $Z$-scores (both $P \leq 0 \cdot 001$ ), while those from the highest SES households had higher waist-to-height ratio $Z$-scores $(P=0 \cdot 031)$. Similarly, those from the highest SES households had about twofold higher odds of overweight/ obesity and central obesity (both $P<0 \cdot 05$; Tables 2 and 3 ).

\section{Discussion}

The present study has described key predictors of weight status and central obesity among adolescents aged 10-20 years living in rural South Africa. The study has demonstrated that significant predictors are at child level including age, sex and pubertal development; at maternal level including mother's age; and at household level including highest education of the household head, food security status and SES. Identifying context-specific predictors of the increasingly important problem of child obesity is an important step in its prompt containment given its link to the risk for paediatric metabolic diseases in $\mathrm{LMIC}^{(26,27)}$.

The study reports a substantial prevalence of overweight/obesity particularly among girls, which is consistent with other findings in South $\mathrm{Africa}^{(28)}$. This is also consistent with findings in other LMIC undergoing a nutrition transition ${ }^{(26,29)}$. Substantial levels of child overweight/obesity have been reported in Africa particularly in North African countries such as Egypt, in other southern African countries, and even in countries as poor as Malawi ${ }^{(30)}$.

Consistent with other studies ${ }^{(10)}$, child-level factors emerged as key predictors of adolescent weight status and central obesity. Obesity increased with increase in 
age and was associated with pubertal development. This may reflect the effect of factors such as increased sedentary behaviour and decreased physical activity with age and pubertal onset ${ }^{(10,31)}$. These changes are explained by physical, social and emotional changes ${ }^{(32)}$. However, sedentary behaviour and physical activity, which could have influenced the outcomes, were not measured in the present study. The increased risk of obesity among girls in our study is in keeping with studies in other LMIC ${ }^{(29)}$ and in South Africa in particular ${ }^{(6)}$. Several factors may explain the sex differences in obesity: (i) biologically, energy needs differ for boys and girls and also in relation to rate of growth ${ }^{(33)}$; and (ii) behaviourally, boys are generally more physically active than girls especially during adolescence ${ }^{(11,32,34)}$. Concerns about body image, particularly among adolescent girls, can lead to problematic eating behaviours such as irregular meal patterns which may result in increased weight gain $^{(35)}$. Differential problematic eating behaviours by sex have been reported among youth in South Africa ${ }^{(36)}$.

While many studies have documented the effect of mother's age on child undernutrition, little has been documented on the effect of mother's age on adolescent obesity. The present study indicates that adolescents with older mothers are significantly more likely to be centrally obese. Although this needs further study, we postulate that this may be associated with less knowledge of the adverse health effects of obesity in the older age group, particularly given their lower literacy levels in the study community $^{(37)}$, and a stronger adherence to the cultural value ascribed to larger women. This may lead to practices that promote obesity since studies indicate that parents serve as role models for their children; for example, children often prefer foods eaten by their parents. Additionally, older mothers may monitor their child's behaviour less, which may affect the child's diet and physical activity patterns ${ }^{(10)}$.

The household-level predictors of obesity observed in the present study include household head's highest education level, food security and SES. Education may affect nutritional status through knowledge of a healthy diet and of the harmful effects of overnutrition. It may also affect income levels leading to sedentary lifestyles, availability of food and dietary changes. In our study, education less than secondary certificate was protective, while secondary and tertiary education - levels that could lead to higher SES - were not significantly associated with obesity. There was, however, a tendency towards a positive association. There seems, therefore, to be a mixed effect: while on the one hand education is protective, it also leads to higher BMI and central obesity. However, the household head's education level was observed to be significantly associated with SES (although there was no significant collinearity); this may indicate attenuation of each of these factors in the overall effect.

Available literature on the association between food (in)security and childhood/adolescent overweight/obesity is generally conflicting ${ }^{(38,39)}$. In high-income countries, food insecurity is often associated with child and adolescent overweight/obesity $^{(38)}$ because the poor may opt for cheaper, energy-dense processed foods ${ }^{(40)}$. However, there are also studies that indicate otherwise ${ }^{(39)}$. Similarly, in the limited literature from LMIC, some studies have found a positive association between food insecurity and overweight/obesity, and others the opposite ${ }^{(38)}$. The Agincourt study area, a former homeland, has low local food production; hence food security may relate strongly to the ability to afford purchased (processed) food.

The relationship between SES and obesity varies across different countries depending on economic development ${ }^{(41)}$. The pathways through which SES is associated with overnutrition include income, education and occupation, resulting in behaviours which influence the balance between energy intake, expenditure and metabolism ${ }^{(42)}$. The positive relationship found in the present study is in keeping with several other studies in $\operatorname{LMIC}^{(9,29,41)}$, but contradicts findings in high-income countries ${ }^{(41)}$. However, even in high-income countries such as the USA the reverse association between SES and overnutrition is said to be weakening over time and is population specific, particularly in children ${ }^{(43,44)}$. Although South Africa is classified as a middle-income country, there is high intra-country inequality with regard to income distribution and high levels of poverty in some regions. The study area is lowincome, located in one of the three provinces with the highest poverty rates in South Africa ${ }^{(14)}$. The relationship observed may be associated with the sedentary lifestyle and ability to afford processed foods of those in the highest SES category relative to those in the lowest SES category. Results not shown on the assets that constitute the socioeconomic score indicate that while almost all of the highest SES households owned a television (96\%), slightly below $50 \%$ of the lowest SES did; while 35\% of the highest SES households owned a car, only $7 \%$ of the lowest SES households did. SES and food security variables were significantly associated, although the association was not significantly collinear. This may indicate attenuation of the overall effect of each of these variables.

Extensive labour migration to larger towns outside the study area ${ }^{(15,16)}$ facilitates the transfer and introduction of urban practices to rural settings with consequent change in diet, resulting in substitution of traditional foods with energy-dense processed foods as seen in some settings in South Africa ${ }^{(45)}$. While those in higher SES households may afford to purchase such foods, the poorest may not and would therefore rely on limited home-grown produce and wild foods. Consumption of animal products and energy-dense foods has been associated with overweight/ obesity in countries undergoing nutrition transition ${ }^{(1)}$.

The present study did not address the association between weight status and central obesity and their more proximate determinants; i.e. imbalance between energy intake and expenditure such as dietary patterns and 
physical activity. However, there is little controversy concerning these factors. The study therefore focused on the more distal determinants which give rise to the imbalance and for which current evidence is more limited. A further limitation relates to the measurement of food security, which was designed primarily as a simple tool to measure trends in household food security in the Agincourt health and sociodemographic surveillance area over time rather than to detail multiple dimensions of food security.

Our study has identified key predictors of adolescent weight status and central obesity in rural South Africa. The findings show that female sex, pubertal development, being in a household that is food secure and of higher SES (measured using household assets) are the most important predictors of weight status and central obesity. These findings indicate a need for gender-sensitive intervention strategies that take into consideration pubertal development, relative wealth and related behaviours in curbing the rising problem of child and adolescent obesity. Further research into dietary patterns and physical activity among adolescents in the study area and related settings, and their associations with child- and household-level characteristics, is necessary for effective interventions.

\section{Acknowledgements}

Sources of funding: Funding from the National Research Foundation (NRF) and the Medical Research Council (MRC), South Africa, is acknowledged. The Agincourt health and sociodemographic surveillance system is funded by the Wellcome Trust, UK (069683/Z/02/Z) and is a member of the INDEPTH Network. E.W.K.-M. had a $\mathrm{PhD}$ fellowship funded by the Flora and William Hewlett Foundation, USA, while S.A.N. was on a Wellcome Trustfunded fellowship. Conflict of interest: The authors have no conflict of interest. Authors' contributions: E.W.K.-M. contributed to study design, project implementation and management, data analysis and writing of the manuscript. K.K. contributed to study design, overall project co-ordination and review of the manuscript. J.M.P. contributed to study design and review of the manuscript. S.M.T. contributed to study design and review of the manuscript. K.K.-G. contributed to analytic guidance and review of the manuscript. S.A.N. contributed to study design, overall project management, analytic guidance and review of the manuscript. All authors read and approved the final manuscript for submission. Acknowledgments: We acknowledge logistical support from the MRC/Wits Rural Public Health and Health Transitions Research Unit (Agincourt) during data collection and from the African Population and Health Research Center, Kenya, during preparation of the manuscript. We thank Dr Mark Collinson, Dr Xavier Gomez-Olivé and Professor David Dunger for their technical contribution during design of the study. We are grateful to the data collection team and the LINC office team at the MRC/Wits-Agincourt Unit, specifically Rhian Twine, Jeffrey Tibane and Audrey Khosa for their role in community mobilisation. We also acknowledge the training team and the data entry team from the Birth-to-Twenty Programme, University of the Witwatersrand, South Africa, funded by the Wellcome Trust, UK (077210/Z/05/Z).

\section{References}

1. Popkin BM \& Gordon-Larsen P (2004) The nutrition transition: worldwide obesity dynamics and their determinants. Int J Obes Relat Metab Disord 28, Suppl. 3, S2-S9.

2. World Health Organization (2002) The World Health Report 2002: Reducing Risks, Promoting Healthy Life. Geneva: WHO; available at http://www.who.int/whr/2002/en/ whr02_en.pdf

3. Bibbins-Domingo K, Coxson P, Pletcher MJ et al. (2007) Adolescent overweight and future adult coronary heart disease. $N$ Engl J Med 357, 2371-2379.

4. Dietz WH (1998) Childhood weight affects adult morbidity and mortality. J Nutr 128, Suppl 2, S411-S414.

5. Department of Health, Medical Research Council \& ORC Macro (2007) South African Demographic and Health Survey 2003. Pretoria: Department of Health; available at http://www.measuredhs.com/pubs/pdf/FR206/FR206.pdf

6. Jinabhai CC, Reddy P, Taylor M et al. (2007) Sex differences in under and over nutrition among school-going Black teenagers in South Africa: an uneven nutrition trajectory. Trop Med Int Health 12, 944-952.

7. Labadarios D, Swart R, Maunder EMW et al. (2008) National Food Consumption Survey-Fortification Baseline (NFCS-FB-I): South Africa, 2005. S Afr J Clin Nutr 21, Suppl. 2, 245-300.

8. Kimani-Murage E, Kahn K, Pettifor J et al. (2010) The prevalence of stunting, overweight and obesity, and metabolic disease risk in rural South African children. BMC Public Health 10, 158.

9. Griffiths PL, Rousham EK, Norris SA et al. (2008) Socioeconomic status and body composition outcomes in urban South African children. Arch Dis Child 93, 862-867.

10. Davison KK \& Birch LL (2001) Childhood overweight: a contextual model and recommendations for future research. Obes Rev 2, 159-171.

11. Kruger R, Kruger HS \& Macintyre UE (2006) The determinants of overweight and obesity among 10- to 15-year-old schoolchildren in the North West Province, South Africa - the THUSA BANA (Transition and Health during Urbanisation of South Africans; BANA, children) study. Public Health Nutr 9, 351-358.

12. Hargreaves JR, Collinson MA, Kahn K et al. (2004) Childhood mortality among former Mozambican refugees and their hosts in rural South Africa. Int J Epidemiol 33, 1271-1278.

13. Dolan CG, Tollman SM, Nkuna VG et al. (1997) The links between legal status and environmental health: a case study of Mozambican refugees and their hosts in the Mpumalanga (Eastern Transvaal) Lowveld, South Africa. Health Hum Rights 2, 62-84.

14. Gelb S (2003) Inequality in South Africa: nature, causes and responses. http://www.commerce.uct.ac.za/Research_Units/ DPRU/DPRU-Conference2004/Papers/Gelb_Inequality_in_ SouthAfrica.pdf (accessed February 2010).

15. Collinson MA, Tollman SM \& Kahn K (2007) Migration, settlement change and health in post-apartheid South Africa: triangulating health and demographic surveillance with national census data. Scand J Public Health 35, Suppl. 69, S77-S84. 
16. Collinson MA, Tollman SM, Wolff B et al. (2006) Trends in internal labour migration from rural Limpopo Province, male risk behaviour, and implications for the spread of HIV/AIDS in rural South Africa. J Ethn Migr Stud 32, 633-648.

17. Kahn K, Tollman SM, Collinson MA et al. (2007) Research into health, population and social transitions in rural South Africa: data and methods of the Agincourt Health and Demographic Surveillance System. Scand J Public Health 35, Suppl. 69, S8-S20.

18. Lohman TG, Roche AF \& Martorell R (1991) Anthropometric Standardization Reference Manual. Champaign, IL: Human Kinetics Books.

19. Tanner JM (1962) Growth at Adolescence. Oxford: Blackwell.

20. Norris SA \& Richter LM (2005) Usefulness and reliability of Tanner pubertal self-rating to urban black adolescents in South Africa. J Res Adolesc 15, 609-624.

21. Filmer D \& Pritchett LH (2001) Estimating wealth effects without expenditure data - or tears: an application to educational enrollments in states of India. Demography 38, $115-132$.

22. World Health Organization (2009) WHO AnthroPlus for Personal Computers Manual: Software for Assessing Growth of the World's Children and Adolescents. Geneva: WHO.

23. Cole TJ, Bellizzi MC, Flegal KM et al. (2000) Establishing a standard definition for child overweight and obesity worldwide: international survey. BMJ 320, 1240-1243.

24. Ashwell M (2009) Obesity risk: importance of the waist-toheight ratio. Nurs Stand 23, 49-54.

25. World Health Organization (1995) Physical Status: The Use and Interpretation of Anthropometry. Report of a WHO Expert Committee. WHO Technical Report Series no. 854. Geneva: WHO.

26. Kelishadi R (2007) Childhood overweight, obesity, and the metabolic syndrome in developing countries. Epidemiol Rev 29, 62-76.

27. Reilly JJ, Methven E, McDowell ZC et al. (2003) Health consequences of obesity. Arch Dis Child 88, 748-752.

28. Reddy S, Resnicow K, James S et al. (2009) Underweight, overweight and obesity among South African adolescents: results of the 2002 National Youth Risk Behaviour Survey. Public Health Nutr 12, 203-207.

29. Neutzling MB, Taddei JA, Rodrigues EM et al. (2000) Overweight and obesity in Brazilian adolescents. Int J Obes Relat Metab Disord 24, 869-874.

30. de Onis M \& Blossner M (2000) Prevalence and trends of overweight among preschool children in developing countries. Am J Clin Nutr 72, 1032-1039.

31. Hardy LL, Bass SL \& Booth ML (2007) Changes in sedentary behavior among adolescent girls: a 2.5-year prospective cohort study. J Adolesc Health 40, 158-165.
32. Lindquist CH, Reynolds KD \& Goran MI (1999) Sociocultural determinants of physical activity among children. Prev Med 29, 305-312.

33. Wisniewski AB \& Chernausek SD (2009) Gender in childhood obesity: family environment, hormones, and genes. Gend Med 6, Suppl. 1, S76-S85.

34. Reddy SP, Panday S, Swart D et al. (2003) Umthenthe Ublaba Usamila - The South African Youth Risk Behaviour Survey 2002. Cape Town: South African Medical Research Council; available at http://www.mrc.ac.za/healthpromotion/ reports.htm

35. Neumark-Sztainer D, Paxton SJ, Hannan PJ et al. (2006) Does body satisfaction matter? Five-year longitudinal associations between body satisfaction and health behaviors in adolescent females and males. J Adolesc Health 39, 244-251.

36. le Grange D, Telch CF \& Tibbs J (1998) Eating attitudes and behaviors in 1,435 South African Caucasian and nonCaucasian college students. Am J Psychiatry 155, 250-254.

37. Collinson MA (2009) Striving against adversity: the dynamics of migration, health and poverty in rural South Africa. PhD Thesis, Umeå University.

38. Kursmark M \& Weitzman M (2009) Recent findings concerning childhood food insecurity. Curr Opin Clin Nutr Metab Care 12, 310-316.

39. Amuna P \& Zotor FB (2008) Epidemiological and nutrition transition in developing countries: impact on human health and development. Proc Nutr Soc 67, 82-90.

40. Drewnowski A (2003) Fat and sugar: an economic analysis. J Nutr 133, Suppl. 3, S838-S840.

41. Wang Y (2001) Cross-national comparison of childhood obesity: the epidemic and the relationship between obesity and socioeconomic status. Int J Epidemiol 30, 1129-1136.

42. Sobal J (1991) Obesity and socioeconomic status: a framework for examining relationships between physical and social variables. Med Anthropol 13, 231-247.

43. Wang Y \& Zhang Q (2006) Are American children and adolescents of low socioeconomic status at increased risk of obesity? Changes in the association between overweight and family income between 1971 and 2002. Am J Clin Nutr 84, 707-716.

44. Matijasevich A, Victora CG, Golding J et al. (2009) Socioeconomic position and overweight among adolescents: data from birth cohort studies in Brazil and the UK. BMC Public Health 9, 105.

45. Vorster HH, Venter CS, Wissing MP et al. (2005) The nutrition and health transition in the North West Province of South Africa: a review of the THUSA (Transition and Health during Urbanisation of South Africans) study. Public Health Nutr 8, 480-490. 